\title{
Commissioning services for people with dementia: how to get it right
}

\author{
Steve lliffe $e^{1}$
}

The Psychiatrist (2013), 37, 121-123, doi: 10.1192/pb.bp.112.040329

${ }^{1}$ University College London, UK Correspondence to Steve lliffe (s.iliffe@ucl.ac.uk)

First received 12 Jun 2012, final review 6 Sep 2012, accepted 24 Oct 2012

\begin{abstract}
Summary The current emphasis on improving the quality of dementia services is welcome, but it treats dementia as if it were separable from complex comorbidities, disability and frailty. As a consequence, dementia can overshadow other problems, from heart failure to multisystem failure at the end of life, which may be poorly managed. Three ways in which old age psychiatrists can reconnect dementia with the diseases and disorders of later life are described in this editorial. The first is to improve skills in general practice so that general practitioners (GPs) can take on the bulk of the clinical work of both diagnosis and management of dementia and its comorbidities, while specialists retain complex decision-making and management tasks. The second is for old age psychiatrists to function as consultants to social enterprises run by GPs for the purpose of managing almost all patients with dementia in general practice. The third is for community geriatricians and old age psychiatrists to work together in integrated organisations that take full clinical responsibility for older people with dementia.
\end{abstract}

Declaration of interest S.I. is a member of a locality commissioning board in north-west London and Associate Director of the UK Dementias and Neurodegenerative Diseases Research Network (DENDRON), part of the National Institute for Health Research.

\section{Government guidance for commissioning dementia services}

Dementia syndrome is a complex clinical problem of growing proportions that presents commissioners with many dilemmas. Not only is early recognition often difficult, with ample scope for misattribution of symptoms, but no disease-modifying treatment exists and symptomatic treatments have weak effects. The high costs of dementia to health and social care and the policy imperative to improve suboptimal services are reflected in the Department of Health's allocation of resources to a dementia commissioning pack. ${ }^{1}$

This commissioning pack does not specify exactly who does the tasks of diagnosing, treating and supporting people with dementia, but it was designed for old age psychiatrists and general practitioners (GPs), the two medical disciplines that manage most patients with dementia syndrome. It treats dementia as a stand-alone problem which can be managed by a modular system of service specifications for different points on the disease trajectory. The processes of diagnosis and counselling fit into one module, the acute in-patient episode into another, and the management of behavioural and psychological symptoms into a third. Clinical responsibility rests with GPs, except during the formal diagnostic process and during acute admissions to hospital. Long-term follow-up of patients by specialists is discouraged.
The commissioning pack has many advantages for clinical commissioners. It allows them to avoid re-inventing service specifications, contains a costing tool that uses an upstream budget to predict downstream gains, and identifies the quality indicators that would help commissioners to judge service performance. The modules can be used individually, and the package can be edited to fit the landscape of local services.

These are positive attributes, but the dilemmas remain because dementia syndrome is not a stand-alone condition, but part of a cluster of comorbidities, disabilities and frank frailty that progresses invariably to death. Comorbidities in people with dementia both reduce life expectancy and increase service use. Life expectancy after the diagnosis of dementia is so short that a palliative care stance seems more appropriate than treating it as a long-term condition. Part of the increase in service use comes from dementia's overlap with frailty, an unstable state in which minor events can have major consequences, which then contribute to the short life expectancy.

\section{Dementia: not a clear-cut picture}

A large prospective population study has shown that survival from symptom onset in dementia is 4.5 years, ${ }^{2}$ with longer survival in younger people. Survival from diagnosis, established in a large retrospective population 
study, is 3.5 years, ${ }^{3}$ again with longer survival in the younger old. Most people with dementia have major comorbidities: $57 \%$ have two or more expressions of vascular disease and/ or diabetes, ${ }^{4}$ which predict higher mortality independent of age. ${ }^{5,6}$ The incidence of recurrent stroke is doubled, ${ }^{7}$ and people with dementia show greater functional and nutritional deficits, plus higher illness burden and costs. ${ }^{8}$ Comorbidities may be 'overshadowed' by dementia, with consequent poorer management of acute myocardial infarction and atrial fibrillation, and less prevention of secondary or recurrent stroke.

Frailty further complicates the dementia picture, because reduction in reserve capacity across multiple physiological systems pushes them over the threshold of clinical failure. This reduction in reserve capacity develops through the cumulative effect of individual deficits - the more problems individuals have, the more likely they are to be frail. ${ }^{9}$ This accumulation of losses may seem innocent, but it is not. Each one-unit increase in frailty (measured using a scale including grip strength, timed walk, body composition and fatigue) is associated with a $63 \%$ increase in mild cognitive impairment risk. ${ }^{10}$

Although the course of dementia syndrome always ends in death, there are substantial gaps in the quality of end-of-life care for people with dementia. ${ }^{11}$ The common problems are achieving adequate pain control, deciding on appropriate nutrition and maintaining hydration. Prognostication is difficult in dementia and care planning can be weak or ineffective. One result is that people with dementia at the end of life are admitted as emergencies to acute hospital wards.

\section{Patients with comorbid dementia: whose responsibility?}

The Department of Health commissioning package is very useful but it does not address the realities of comorbidity, frailty and end-of-life care. These confounding factors need to be added to the package by clinical commissioners, who will need to consider what skills they can mobilise to enhance services for people with dementia. This is where problems begin. Old age psychiatrists may not feel comfortable with assessment of physical pathologies as well as cognitive impairment and behavioural and psychological symptoms. The obvious source of clinical expertise to manage complex needs is general practice, but GPs repeatedly report that they lack confidence in managing patients with dementia, and they struggle with frailty too. Incentivisation of dementia care may encourage GPs to acquire the skills needed, but the Quality and Outcomes Framework has incentivised diagnosis and annual management reviews since 2006, and there has been little or no increase in the incidence or prevalence of recorded dementia. The reasons for this are not clear, but therapeutic nihilism about dementia is still evident, even if declining. ${ }^{12}$

\section{Three proposals on improving care in dementia}

\section{Shared general and specialist care}

There seem to me to be three options for improving care of people with dementia syndrome. The first is an enhanced version of current practice, in which systematic GP follow-up is supported by specialists' support and advice, using multidisciplinary collaboration to guide clinical interventions. This would require some skill transfer from specialists to generalists, and possibly the application of case management methods by practice nurses to people with dementia. Both of these are significant changes, especially the implementation of case management, which has yielded disappointing results for people with dementia ${ }^{13}$ and for older people with multimorbidity generally. ${ }^{14}$ Specialists would then be responsible for solving complex problems, such as difficult diagnoses, care in acute hospitals and the use of antipsychotics. They would be called on to advise about management of challenging behaviour, and about end-of-life care, but not to undertake routine follow-up. Such evidence as there is suggests that this may be a productive approach to the needs of care home residents, ${ }^{15-17}$ but it is not clear whether it would work well for community-dwelling older people with dementia. Of the three options this one goes with the grain of both practice and evidence, and would be the safest investment.

\section{GP-led social enterprise}

The second option is a variant of the first, in which services are integrated into a single organisational entity (a social enterprise) led by GPs who hire specialists directly. This is the Gnosall model, promoted by old age psychiatrist David Jolley and GP Ian Greaves in Staffordshire. ${ }^{18,19}$ 'General practitioner provider organisations' of this kind are built by enthusiasts who create good working relationships across disciplines, but it is not clear how reproducible they are, and investment in them may be a gamble. Nevertheless, politicians are interested in them as exemplars of new ways of working.

\section{Specialist-led service}

The third option is to take advantage of the freedoms offered by the new commissioning environment to create an alternative service design. In this alternative model old age psychiatrists and community geriatricians run a complex needs/frailty/dementia service, replacing the GP as lead clinicians for this patient group. There is a precedent for this outside the UK, in Holland's discipline of 'nursing home physician', a form of specialisation that takes 2 years from qualification, compared with 3 years for a GP and up to 6 years for a specialist. ${ }^{20}$ Service models do not often travel well across national boundaries, and both commissioners and specialists may want higher levels of skill than they might perceive in the Dutch model, so this could be a challenging option for investors.

The South West Division of the Royal College of Psychiatrists voted on these three options at its May 2012 meeting. The third option won most votes, and the first option came second. Few wanted to be in a social enterprise run by GPs. Which option would you choose?

\section{About the author}

Steve Iliffe is Professor of Primary Care for Older People at the Department of Primary Care and Population Health, University College London, a 
member of a locality commissioning board in north-west London, and Associate Director of the UK Dementias and Neurodegenerative Diseases Research Network (DENDRON), London, UK

\section{References}

1 Department of Health. Dementia commissioning pack. Department of Health, 2011 (http://www.dh.gov.uk/health/2011/07/dementiacommissioning-pack).

2 Xie J, Brayne C, Matthews FE. Survival times in people with dementia: analysis from population based cohort study with 14 year follow-up. BMJ 2008; 336: 258-62.

3 Rait G, Walters K, Bottomley C, Petersen I, Iliffe S, Nazareth I. Survival of people with a clinical diagnosis of dementia in primary care. BMJ 2010; 341: c3584.

4 Connolly A, lliffe S, Gaehl E, Campbell S, Drake R, Morris J, et al. Quality of care provided to people with dementia: utilisation and quality of the annual dementia review in general practice. Br J Gen Pract 2012; 62: e91-8.

5 Gambassi G, Landi F, Lapane KL, Sgadari A, Mor V, Bernabei R. Predictors of mortality in patients with Alzheimer's disease living in nursing homes. J Neurol Neurosurg Psychiatry 1999; 67: 59-65.

6 Larson EB, Shadlen M-F, Wang L, McCormick WC, Bowen JD, Teri L, et al Survival after initial diagnosis of Alzheimer's disease. Ann Intern Med 2004; 140: 501-9.

7 Moroney JT, Bagiella MS, Tatemichi TK, Paik MC, Stern Y, Desmond DW. Dementia after stroke increases the risk of long-term stroke recurrence. Neurology 1997; 48: 1317-25.

8 Zekry D, Herrmann FOR, Grandjean R, Meynet MP, Michel JP, Gold G, et al. Demented versus non-demented very old inpatients: the same comorbidities but poorer functional and nutritional status. Age Ageing 2008; 37: 83-9.

9 Rockwood K, Mitnitski A. Frailty in relation to the accumulation of deficits. J Gerontol A Biol Sci Med Sci 2007; 62: 722-7.
10 Boyle PA, Buchman AS, Wilson RS, Leurgans SE, Bennett DA. Physical frailty is associated with incident mild cognitive impairment in community-based older persons. J Am Geriatr Soc 2010; 58: 248-55.

11 Sampson EL, Gould V, Lee D, Blanchard MR. Differences in care received by patients with and without dementia who died during acute hospital admission: a retrospective case note study. Age Ageing 2006; 35: 187-9.

12 Iliffe $S$, Wilcock J. The identification of barriers to the recognition of and response to dementia in primary care using a modified focus group method. Dementia 2005; 4: 73-85.

13 Pimouguet C, Lavaud T, Dartigues JF, Helmer C. Dementia case management effectiveness on health care costs and resource utilization: a systematic review of randomized controlled trials. J Nutr Health Aging 2010; 14: 669-76.

14 Goodman C, Drennan V, Davies S, Massey H, Gage H, Scott C, et al. Nurses as Case Managers in Primary Care: The Contribution to Chronic Disease Management (Project Report). National Institute for Health Research Service, 2010.

15 Gloth F, Gloth M. A comparative effectiveness trial between a postacute care hospitalist model and a community-based physician model of nursing home care. J Am Med Dir Assoc 2011; 12: 384-6.

16 Crotty M, Halbert J, Rowett D, Giles L, Birks R, Williams H, et al. An outreach geriatric medication advisory service in residential aged care: a randomised controlled trial of case conferencing. Age Ageing 2004; 33: 612-7.

17 Davies SL, Goodman C, Burn F, Victor C, Dickinson A, Iliffe S, et al. A systematic review of integrated working between care homes and health care services. BMC Health Serv Res 2011; 11: 320

18 Greening L, Greaves I, Greaves N, Jolley D. Positive thinking on dementia in primary care: Gnosall Memory Clinic. Community Pract 2009; 82: 20-3.

19 Jolley D, Greaves I, Clark M. Memory clinics and primary care: not a question of either/or. BMJ 2012; 344: e4286.

20 European Medical Association. Situation in the member states of the European Union: Netherlands. EMA (http://www.emanet.org/ pg-netherlands.cfm) 